\title{
Storage Location Assignment with Fuzzy PROMETHEE Method in Warehouse Systems with Uncertain Demand
}

\author{
Mehmet Akif Yerlikaya ${ }^{1, *}$ \\ ${ }^{1}$ Bitlis Eren University, Faculty of Engineering and Architecture Industrial Engineering Department, Bitlis, TURKEY \\ Email: mayerlikaya@beu.edu.tr \\ *Corresponding Author: Mehmet Akif Yerlikaya, Email: mayerlikaya@beu.edu.tr
}

How to cite this paper: Mehmet Akif Yerlikaya (2020). Storage Location Assignment with Fuzzy PROMETHEE Method in Warehouse Systems with Uncertain Demand. Journal of the Institute of Electronics and Computer, 2, 142-150. https://doi.org/10.33969/JIEC.2020.21009.

Received: Ocotober 6, 2020

Accepted: December 18, 2020

Published: December 28, 2020

Copyright () 2020 by author(s) and Institute of Electronics and Computer. This work is licensed under the Creative Commons Attribution International License (CC BY 4.0).

http://creativecommons.org/licenses/by/4.0/

\begin{abstract}
Storage location assignment is an important decision problem in warehouse operations management. Because the main purpose of the storage location assignment system is to create various parameters to facilitate the diagnosis and positioning of the products in the warehouse. In addition, time spent on storage activities is an important factor in the demand cycle. However, uncertainty in product demands causes various problems in assigning products to storage locations. Therefore, it is necessary to research viable and sustainable tools in cases of uncertainty. One of these tools is fuzzy decision making methods, which are frequently used in the literature and give effective results. In this study, it is proposed to rank the products with the Fuzzy PROMETHEE (F-PROMETHEE) method under qualitative criteria for warehouse systems where the demand is uncertain and assign them to the most suitable storage locations according to this rank. The effectiveness of the proposed approach has been tested with a small sample problem. Criteria addressed for this problem are demand, profitability and sensitivity. Solution results have shown that the proposed approach is effective.
\end{abstract}

\section{Keywords}

Warehouse, Order Picking, Storage location assignment, Fuzzy PROMETHEE, PROMETHEE

\section{Introduction}

Warehouse generally refers to the storage of raw materials and products that input businesses. However, with the development of the concept of supply chain management, storage has gained a different dimension. Today, it is very important for businesses to realize the efficient placement of warehouses and to make efficient in warehouse activities. Ineffective warehouse layout causes financial and time losses in businesses. The importance given to the warehouse storage activities of the 
companies that want to gain competitive advantage is increasing. Businesses aim to maximize their profits by reducing their costs with various improvements in warehouse organization.

In order picking systems, products must be placed in the most suitable warehouse locations before picking to meet customer demands on time. Time spent for storage activities is an important factor in the total time spent in the demand cycle. However, when product demands are not known, various problems may arise in the assignment of products to suitable storage locations. Therefore, it is necessary to research viable and sustainable tools in cases of uncertainty. One of these tools is fuzzy decision making methods, which are frequently used in the literature and give effective results.

The literature studies on product assignment are two types: storage location assignment according to single criterion and storage location assignment according to multiple criteria. Single criteria storage location assignment studies are aimed at minimizing the storage cost through simulation and mathematical model. Multi-criteria storage location assignment studies are related to the ranking of the products and their assignment to storage locations considering more than one criterion. However, studies on storage location assignment with fuzzy decision making in warehouse systems with uncertainty are not available in the literature. Fontana and Calvante [1] listed the products taking into account the characteristics that are important for stock strategies and the physical locations of the products in the warehouse. They used the ELECTRE III method to evaluate and rank these alternative products. Fontana and Calvante [2] determined the best alternative location for product assignment in a warehouse, considering multiple criteria for product assignment in the warehouse. Silva et al. [3] proposed a multi-criteria decision model for assigning and ranking products to shelf locations in a warehouse. Fontana and Nepomuceno [4] proposed a multi-criteria decision model to realize the product classification and solve the storage location assignment problem in a multi-layered warehouse. Micale et. al. [5] determined storage locations for products with an integrated ELECTRE TOPSIS based approach due to the multi-criteria structure of the storage location assignment problem. 
In this study, for warehouse systems where the demand is uncertain, it is proposed to rank the products with the F-PROMETHEE method under qualitative criteria and assign them to the most suitable storage locations according to this order. For this, product assignment is explained in the second section and Fuzzy PROMETHEE in the third section. In the fourth section, a solution proposal is presented for the proposed approach.

\section{Storage Location Assignment}

The strategic storage decision affects almost all key performance indicators of a warehouse, such as order picking time, storage space and labor utilization rate. Planning in warehouses is about inventory management and storage location assignment. A good inventory management can also reduce storage costs. On the other hand, a good policy for storage location assignment can reduce the average order picking time for order picking and storage. In particular, to reduce order picking distance in warehouses with a single input/output point, products with higher effectiveness are placed closest to the input/output point. A sample warehouse structure is given in Figure-1.

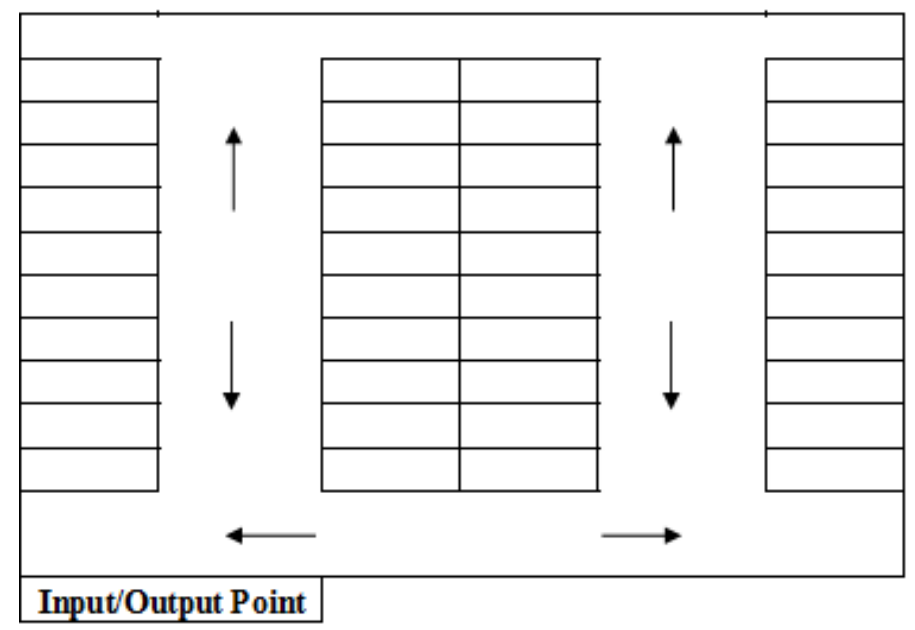

Delivery Point

Figure 1. A sample warehouse layout

In order picking systems, products must be placed in the most suitable locations in 
the warehouse before they are picked to meet customer demands on time. Successful companies offer the right products to the right customers at the right time, in the right place and at the right price. Time spent for storage activities is an important factor in the total time spent in the demand cycle. Therefore, it is necessary to research viable and sustainable tools to minimize this time [2]. The efficiency of an order picking process largely depends on the storage policy used [6]. Turner [7] has discussed 8 storage policies depending on his literature research: Random policy, dedicated policy, class-based policy, cycle-based policy, volume-based policy, shared policy, duration of stay policy, and activity-based policy.

\section{Fuzzy PROMETHEE}

Mathematical features and ease of use are the basis for the very common use of the PROMETHEE method. However, the input values used in this method are very likely to make false conclusions by making false assessments due to the uncertainty and turbidity that occurs when decision-makers are based on their thoughts and experiences, and therefore expressed in linguistic terms. Le Teno and Mareschal [8] were developed the Fuzzy PROMETHEE (B-PROMETHEE) method, which is a combination of fuzzy numbers and PROMETHEE method to prevent the problems that this uncertainty may cause [9].

In this study, B-PROMETHEE method was applied as suggested by Goumas and Lygerou [10]. Therefore, all operations and calculations in the PROMETHEE method are carried out with fuzzy numbers, and the preference threshold values ( $q$ and $p$ ) and weights remain the exact number. $q$ and $p$ are not fuzzy numbers to prevent vague evaluations due to the stretched form of a fuzzy number. Likewise, weights cannot be used as a fuzzy number in the process solution since the sum of the weights must be 1 in the PROMETHEE method [9].

The linear preference function (Type 5), which is most frequently used in B-PROMETHEE applications and which is most suitable for the characteristic of the problem, has been chosen and shown in the equation (1).

$$
\begin{array}{cc}
\mathrm{P}(\mathrm{a}, \mathrm{b})=0, & \mathrm{x} \leq \mathrm{q} \\
\mathrm{P}(\mathrm{a}, \mathrm{b})=(\mathrm{x}-\mathrm{q}) /(\mathrm{p}-\mathrm{q}), & \mathrm{q}<\mathrm{x}<\mathrm{p}
\end{array}
$$




$$
\mathrm{P}(\mathrm{a}, \mathrm{b})=1, \quad \mathrm{x}>\mathrm{p}
$$

When using the F-PROMETHEE method, which calculates with fuzzy numbers, the $\mathrm{x}$ value showing the difference between the performances of $\mathrm{a}$ and $\mathrm{b}$ alternatives is expressed as a fuzzy number $\mathrm{x}=(\mathrm{n}, \mathrm{c}, \mathrm{d})$ and changes as shown in equation (2) and the figure-2.

$$
\begin{array}{cr}
\mathrm{P}(\mathrm{a}, \mathrm{b})=0, & \mathrm{n}-\mathrm{c} \leq \mathrm{q} \\
\mathrm{P}(\mathrm{a}, \mathrm{b})=((\mathrm{n}, \mathrm{c}, \mathrm{d})-\mathrm{q}) /(\mathrm{p}-\mathrm{q}), & \mathrm{q} \leq \mathrm{n}-\mathrm{c} \quad \text { and } \quad \mathrm{n}+\mathrm{d} \leq \mathrm{p} \\
\mathrm{P}(\mathrm{a}, \mathrm{b})=1, & \mathrm{n}+\mathrm{d} \geq \mathrm{p}
\end{array}
$$

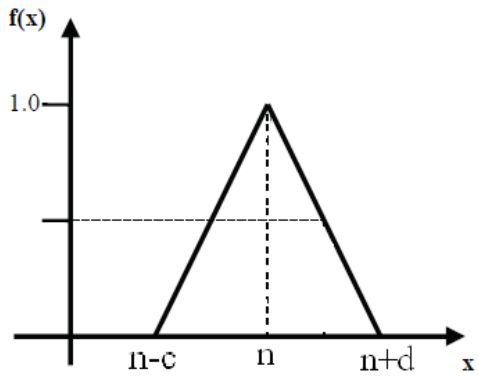

Figure 2. Triangular representation of the fuzzy number $\mathrm{x}=(\mathrm{n}, \mathrm{c}, \mathrm{d})$

It is necessary to have the basic knowledge of operations with fuzzy numbers in

\begin{tabular}{|c|c|}
\hline Addition & $(m, a, b)_{L R}+(n, c, d)_{L R}=(m+n, a+c, b+d)_{L R}$ \\
\hline Get the opposite & $-(m, a, b)_{L R}=(-m, b, a)_{L R}$ \\
\hline Subtract & $(m, a, b)_{L R}-(n, c, d)_{L R}=(m-n, a+d, b+c)_{L R}$ \\
\hline Multiply by a number & $(m, a, b)_{L R} \times(n, 0,0)_{L R}=(m n, a n, b n)_{L R}$ \\
\hline \multicolumn{2}{|c|}{ Multiply by a fuzzy number : } \\
\hline For $m>0$ ve $n>0$ & $(m, a, b)_{L R} \times(n, c, d)_{L R}=(m n, m c+n a, m d+n b)_{L R}$ \\
\hline
\end{tabular}
order to perform the operations in the new function. The necessary formulas for simple operations with fuzzy numbers are given in table-1.

Table 1. Basic fuzzy operations 


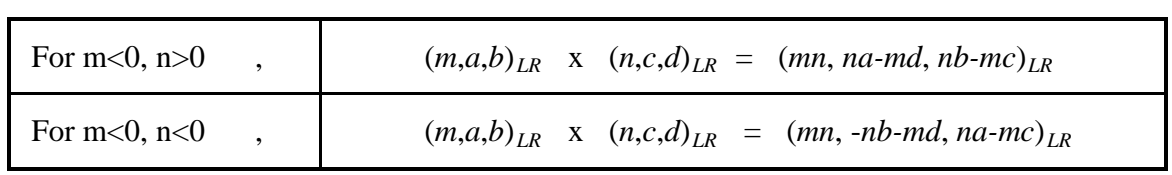

\section{Solution Approach}

The subject of the study is about assigning products to storage locations with fuzzy approach by considering certain criteria for warehouses where demand is uncertain. For this, products are ranked with the fuzzy PROMETHEE method, which allows the uncertainty to be evaluated with linguistic expressions, and it is proposed to be assigned to storage locations accordingly. The fuzzy values to be used in this study are given in table-2. In the solution approach, a sample problem with 5 products and 3 criteria was handled and the datasets used are generated randomly. In this study, the qualitative criteria considered for the ranking of the products are as follows:

- Demand: It refers to the amount that a product may need during a period. Since this amount is uncertain, it is expressed linguistically.

- Profitability: It is the linguistic expression of the profit that can be obtained from a product.

- Sensitivity: It refers to the sensitivity of the customer towards the product. For example, a product that requires delivery in a very short time for the customer has a high sensitivity.

The decision matrix with 5 products-3 criteria based on these criteria is given in table-3. A different solution is made to determine the product rank with the Fuzzy PROMETHEE method to avoid the possibility of misuse that may arise from the uncertainty and fuzziness caused by linguistic terms. Since the criterion weights are equal and the application principles of the PROMETHEE method requires the sum of the criterion weights to be 1 , the values obtained after rinsing the fuzzy variables are re-proportioned to be the total weight values 1 . Using the studies in the literature [8]. The indifference threshold $q$ for the linear preference function to be used in practice is zero for all criteria, and the preference threshold $\mathrm{p}$ is 0.60 . The positive $(\Phi+)$ and negative ( $\Phi-)$ advantages and the exact ranking values ( $\Phi$ net) obtained as a result of the evaluation are given in table 4 . The location is reserved for the 
planned inventory level for each product. These locations are determined according to the rank of prioritization obtained as a result of net flow values. In table-5, the planned inventory level for each product and the locations they are assigned in rank of priority as much as this level are given. Accordingly, the product with the highest net flow value2 is placed closest to the Input/Output point.

Table 2. Linguistic expressions used in the evaluation of the problem and their equivalents as fuzzy triangle numbers

\begin{tabular}{|c|c|}
\hline Linguistic Expressions & Triangle Fuzzy Number Provision \\
\hline Verv High & $(1 ; 0,2 ; 0)$ \\
\hline High & $(0,8 ; 0,15 ; 0.2)$ \\
\hline Medium High & $(0,65 ; 0,15 ; 0.15)$ \\
\hline Medium & $(0,5 ; 0,2 ; 0,15)$ \\
\hline Medium Low & $(0,3 ; 0,15 ; 0,2)$ \\
\hline Low & $(0,15 ; 0,15 ; 0,15)$ \\
\hline Very Low & $(0 ; 0 ; 0,15)$ \\
\hline
\end{tabular}

Table 3. Decision matrix

\begin{tabular}{|c|c|c|c|c|}
\hline \multirow{2}{*}{ Criteria } & & Demand & Profitability & Sensitivity \\
\hline \multirow{3}{*}{ Products } & Product1 & $(0,8 ; 0,15 ; 0,2)$ & $(0 ; 0 ; 0,15)$ & $(0,3 ; 0,15 ; 0,2)$ \\
\cline { 2 - 6 } & Product2 & $(0,5 ; 0,2 ; 0,15)$ & $(0,15 ; 0,15 ; 0,15)$ & $(0,8 ; 0,15 ; 0,2)$ \\
\cline { 2 - 6 } & Product3 & $(0,15 ; 0,15 ; 0,15)$ & $(1 ; 0,2 ; 0)$ & $(0,3 ; 0,15 ; 0,2)$ \\
\cline { 2 - 6 } & Product4 & $(0,5 ; 0,2 ; 0,15)$ & $(0,65 ; 0,15 ; 0.15)$ & $(0,5 ; 0,2 ; 0,15)$ \\
\hline & Product5 & $(0,65 ; 0,15 ; 0.15)$ & $(0,15 ; 0,15 ; 0,15)$ & $(0,5 ; 0,2 ; 0,15)$ \\
\hline
\end{tabular}

Table 4. F-PROMETHEE flow values

\begin{tabular}{|l|c|c|c|c|}
\hline Products & $\Phi^{+}$ & $\Phi^{-}$ & $\Phi^{\text {net }}$ & Rank \\
\hline Product1 & 1 & 1 & 0 & 3 \\
\hline Product2 & 1.67 & 1 & 0.67 & 1 \\
\hline Product3 & 1.16 & 1.67 & -0.51 & 4 \\
\hline Product4 & 1.33 & 0.83 & 0.5 & 2 \\
\hline Product5 & 0.33 & 1 & -0.67 & 5 \\
\hline
\end{tabular}


Table 5. Planned inventory levels and locations

\begin{tabular}{|c|c|c|}
\hline Products & Inventory Level & Location \\
\hline Product2 & 20 & $1-20$ \\
\hline Product4 & 15 & $21-35$ \\
\hline Product1 & 20 & $36-55$ \\
\hline Product3 & 25 & $56-80$ \\
\hline Product5 & 10 & $81-90$ \\
\hline
\end{tabular}

\section{Conclusion}

In order picking systems, products must be placed in the most correct locations in the warehouse before they are picked in order to meet customer demands on time. Time spent for storage activities is an important factor in the total time spent in the demand cycle. However, various problems may arise in the assignment of products to suitable locations in warehouse systems where product demands are uncertain. There are no fuzzy sets studies in the literature that take into account the uncertainty problem in warehouses. In this study, it was proposed to assign products to suitable locations with F-PROMETHEE, which is one of the fuzzy decision making methods that best express the decision status in uncertainty. To test the effectiveness of the proposed approach, a solution was made on a sample problem with 5 products, 3 criteria and 90 locations. The criteria considered was demand, profitability and sensitivity. The solution results revealed the effectiveness of assigning products with the F-PROMETHEE method, using linguistic expressions in cases of uncertainty.

\section{References}

[1] Fontana, M.E., Cavalcante, C.A.V. (2013). "Electre tri methodused to storage location assignment into categories”. Pesquisa Operacional, 33(2), 283-303.

[2] Fontana, M., Calvante, C. (2014). "Using the Efficient Frontier to Obtain the Best Solution for the Storage Location Assignment Problem”. Mathematical Problems in Engineering, DOI: 10.1155/2014/745196.

[3] Silva, D.D., Vasconcelos, N.N., Cavalcante, C.A. (2015). "Multicriteria Decision Model to Support the Assignment of Storage Location of Products in a Warehouse". Mathematical Problems in Engineering, DOI:10.1155/2015/481950.

[4] Fontana, M., Nepomuceno, V. (2017). "Multi-criteria approach for products classification and their storage location assignment”. International Journal of Advanced Manufacturing Technology, 88(9-12), 3205-3216.

[5] Micale, R., La Fata, C.M., La Scalia, G. (2019). “A Combined interval-valued ELECTRE TRI and TOPSIS approach for solving the Storage Location 
Assignment Problem”. Computers \& Industrial Engineering, 135, 199-210.

[6] Muppani, V.R., Adil, G.K. (2008:1). “A branch and bound algorithm for class based storage location assignment”. European Journal of Operational Research, 189(2), 492-507.

[7] Turner, S., 2009. “Joint Multi-item Storage Location Assignment Capacitated Lot Sizing Problem". Electronic Theses and Dissertations, University of Windsor, Canada.

[8] Le Téno, J., F., ve Mareschal, B. (1998). "An interval version of PROMETHEE for the comparison of building products' design with ill-defined data on environmental quality", Eur Journal of Operational Research, 109, 522-529.

[9] Efe, B., Yerlikaya, M.A., Efe, Ö.F. (2016). “İş Güvenliğinde Bulanık Promethee Yöntemiyle Hata Türleri ve Etkilerinin Analizi: Bir İnşaat Firmasında Uygulama". Gümüşhane Üniversitesi Fen Bilimleri Enstitüsü Dergisi, 6(2), 126-137.

[10] Goumas, M., Lygerou, V. (2000). “An extension of the PROMETHEE method for decision making in fuzzy environment: Ranking of alternative energy exploitation projects”, European Journal of Operational Research, 123(3), 606-613. 